\title{
Factors affecting total and "respirable" dose delivered by a salbutamol metered dose inhaler
}

\author{
Mark L Everard, Sunalene G Devadason, Quentin A Summers, Peter N Le Souëf
}

\begin{abstract}
Background - Many factors contribute to the high variability of doses delivered to the lungs of patients using metered dose inhalers (MDIs). Relatively little attention has been paid to the contribution to this variability of the way in which the MDI is handled before the inhalation manoeuvre. Instruction leaflets often recommend procedures at odds with those used for in vitro testing of the device. The standard protocol for in vitro assessment of salbutamol MDIs involves shaking the MDI vigorously for 30 seconds and wasting the first two actuations. Subsequent actuations are introduced into the testing device at five second intervals. Patient instructions do not include a recommendation to waste the first two actuations and recommend a delay of one minute between actuations. A series of experiments was performed to determine whether such differences might be important.

Methods - The total and "respirable"
\end{abstract} doses delivered by a salbutamol MDI (Ventolin, Allen \& Hanburys) under various conditions were assessed with a multistage liquid impinger. The quantity of drug deposited on each stage was measured by an ultraviolet spectrophotometric method. The effect on the delivered dose of not shaking the canister, not wasting the first two doses, waiting 30 seconds between actuations, and using multiple rapid actuations was assessed by comparing the results with those obtained using the standard in vitro testing protocol.

Results - Compared with a standard protocol, it was found that not shaking the MDI before use reduced the total and "respirable" dose by $25 \cdot 5 \%$ and $35 \cdot 7 \%$, respectively. The dose delivered when actuating the MDI at $\mathbf{3 0}$ second intervals was no different from that when intervals of five seconds were used. Two actuations separated by one second had no effect on the total dose but reduced the "respirable" dose by $15 \cdot 8 \%$, while four rapid actuations reduced the total and "respirable" doses by $8 \cdot 2 \%$ and $18 \cdot 2 \%$, respectively. Storing the MDI stem down reduced the total and "respirable" dose delivered in the first actuation by $25 \cdot 0 \%$ and $23 \cdot 3 \%$ despite shaking the MDI before use.

Conclusions - MDIs containing drug in suspension must be shaken before use to resuspend the drug contained in the MDI, but shaking does not alter the composition of the suspension in the metering chamber and hence the dose in the first actuation remains low. Very rapid actuations can reduce the dose delivered per actuation, but salbutamol MDIs can be actuated immediately after a 10 second breath holding pause without affecting the dose delivered. (Thorax 1995;50:746-749)

Keywords: metered dose inhaler, operating conditions, in vitro assessment.

Although metered dose inhalers (MDIs) are the devices most widely used for aerosol therapy, their effectiveness is often adversely influenced by suboptimal use. Recommendations for use vary and this can cause confusion in the minds of patients wishing to use the devices optimally and in those instructing them. Hence, instructions should be as simple as possible.

Protocols used by drug companies for handling MDIs during in vitro assessment of formulations frequently vary from that recommended for clinical use. A typical standard protocol when using a particle sizing device such as a multistage liquid impinger involves shaking the MDI vigorously for 30 seconds and then wasting the first two actuations. The MDI is then actuated a predetermined number of times into the particle sizing device. These actuations are separated by an interval of 5-30 seconds, depending upon the protocol being used, and the MDI is shaken between each actuation.

Instructions for clinical use do not normally include wasting the first actuations and it is frequently stated that actuations should be separated by at least one minute. ${ }^{1-4}$ The delay of one minute between actuations is based on the suggestion that more frequent actuations adversely affect the output and particle size distribution of subsequent actuations ${ }^{125}$ due to cooling of the metering valve.

The importance of these differences is unclear. Protocols used by pharmaceutical companies are presumably designed to maximise reproducibility of dose and particle size. Hence, the routine wastage of two actuations during in vitro testing suggests that these doses may not be as reproducible as subsequent doses, and the use of five second intervals between actuations suggests that a one minute delay is unnecessary.

A multistage liquid impinger was used to assess the effect on total drug output and particle size distribution when a salbutamol MDI (Ventolin, Allen \& Hanburys) was actuated in accordance with several protocols. 


\section{Methods}

The total dose and particle size distribution of the aerosol delivered by the metered dose inhalers was assessed using an Astra High Performance Multistage Liquid impinger (MSLI; Copley UK, Nottingham). Air is drawn through the device at a continuous flow of $60 \mathrm{l} /$ min. After actuating the MDI into the "throat" of the impinger the aerosol is drawn through the device with the entraining air flow. Droplets are deposited upon the throat or one of four stages and the site of deposition is determined by the particle size of the droplet. The device has been calibrated in such a way that all droplets penetrating beyond each stage are smaller than a given diameter; particles $>13 \mu \mathrm{m}, 6.8-13 \mu \mathrm{m}, 3.1-6.8 \mu \mathrm{m}$, and $<3.1 \mu \mathrm{m}$ are deposited on stages $1,2,3$, and 4 , respectively. The dose depositing on stages $3+4$ is often termed the "respirable dose" although the correlation between this figure and the dose delivered to the lungs when MDIs are used by patients is not good.

For each experiment at least 10 actuations of an MDI were introduced into the impinger in order to ensure that sufficient drug was deposited on each stage to obtain accurate results. The amount of salbutamol deposited on the actuator, throat, and each of the stages of the MSLI was measured using the following method. The actuator, throat, and stages of the MSLI were separately washed with approximately $40 \mathrm{ml}$ of methanol; $5 \mathrm{ml} 0.1 \mathrm{M}$ $\mathrm{NaOH}$ was added to each wash and the volume was then made up to a total of $50 \mathrm{ml}$ with methanol. The absorbance $(\lambda=246 \mathrm{~nm})$ of each sample was measured in duplicate $\left(A_{\text {alk }}\right)$ on a spectrophotometer (Hitachi U-2000);0.5 ml concentrated $\mathrm{HCl}$ was added to a $10 \mathrm{ml}$ aliquot of each solution and the absorbance at $246 \mathrm{~nm}$ measured in duplicate $\left(\mathrm{A}_{\mathrm{acid}}\right)$. The absorbance of each solution was obtained by subtracting $A_{\text {acid }}$ from $A_{\text {alk }}$ and the concentration of salbutamol in the samples obtained by using the absorbance of a solution containing a known concentration of salbutamol. The standard curve for salbutamol was linear $\left(r^{2}=1.00\right)$ for concentrations between 0 and $27 \mu \mathrm{g} / \mathrm{ml}$. A known solution of salbutamol was included with each assay, and the coefficient of variation for the absorbance of this solution was $1.9 \%$.

All results are expressed as dose per actuation.

\section{STANDARD PROTOCOL}

The standard protocol used by Glaxo for handling salbutamol MDIs during in vitro testing (personal communication) was used in these experiments, against which modifications to this protocol could be compared. The MDI was stored overnight standing on its base and then shaken vigorously for 30 seconds before the first actuation. The first two actuations were wasted before testing. Ten actuations at five second intervals were then introduced into the impinger and the MDI was shaken vigorously during the intervals between actuations. A total of 11 such experiments was performed.

\section{Omitting shaking}

The salbutamol canister was stored overnight (minimum of 16 hours) on its base. It was gently inverted and was not shaken before the first actuation or between actuations. The first two actuations were wasted and the MDI was then actuated at five second intervals.

\section{Altering the delay between actuations}

(a) The standard protocol was followed but the delay between actuations was increased to 30 seconds $(n=8)$.

(b) Two actuations separated by one second were repeated at five second intervals in order to assess the effect on delivered dose of actuating the canister for a second time immediately after it had been actuated in the standard manner. A total of 10 actuations $(2 \times 5)$ was used for each experiment $(\mathrm{n}=$ 5). The MDI was shaken during the five second intervals.

(c) The MDI was actuated four times at one second intervals. A total of $12(4 \times 3)$ actuations was used with each set of four actuations, being separated by five second intervals $(n=5)$. The canister was shaken in the normal way between the sets of four actuations.

Effect of delay between shaking and actuation

(a) The MDI was shaken for five seconds immediately after each actuation and then left with the stem down for 30 seconds without being disturbed before the next actuation. Ten actuations were performed for each experiment $(n=6)$.

(b) The MDI was then shaken for five seconds immediately after each actuation and left with the stem down for 10 seconds without being disturbed before the next actuation $(n=6)$.

\section{Dose delivered by first actuation}

The first actuation from 10 different MDIs was introduced into the impinger. The MDIs were stored overnight (minimum of 16 hours) before the experiment, shaken for 30 seconds and the initial actuations from each MDI were put through the impinger.

(a) MDIs were stored on their bases with the stems up $(n=6)$.

(b) MDIs were stored with their stems down $(n=6)$.

\section{DATA ANALYSIS}

Statistical analysis of the data was carried out using a one way analysis of variance (ANOVA).

\section{Results}

Results from the standard protocols and subsequent experiments are presented in the table.

\section{Omitting shaking}

Not shaking the canister reduced the total output of drug from the MDI by $25.5 \%(\mathrm{p}<0.01)$ 
Total output ( $\mu \mathrm{g} /$ actuation) and output of particles of $<6 \cdot 8 \mu \mathrm{m}$ and $<3 \cdot 1 \mu \mathrm{m}$ in diameter ( $\mu$ g/actuation) when a salbutamol metered dose inhaler was actuated according to the standard protocol and under a variety of different conditions

\begin{tabular}{|c|c|c|c|}
\hline Protocol & $\begin{array}{l}\text { Total output } \\
\text { ( } \mu \text { g/actuation) }\end{array}$ & $\begin{array}{l}\text { Particles }<6 \cdot 8 \mu m \\
\text { ( } \mu \text { g/actuation) }\end{array}$ & $\begin{array}{l}\text { Particles }<3 \cdot 1 \mu m \\
\text { ( } \mu \text { g/actuation) }\end{array}$ \\
\hline Standard & $109 \cdot 1(7 \cdot 6)$ & $59 \cdot 4(6 \cdot 0)$ & $44 \cdot 6(3 \cdot 2)$ \\
\hline $\begin{array}{l}\text { Omitting shaking: } \\
\text { Unshaken }\end{array}$ & $81 \cdot 3(9 \cdot 2)^{* *}$ & $38 \cdot 2(4 \cdot 5)^{* *}$ & $28 \cdot 7(2 \cdot 5)^{* *}$ \\
\hline $\begin{array}{l}\text { Altering delay betwee } \\
30 \mathrm{~s} \text { intervals } \\
\text { Double actuations } \\
\text { Four actuations }\end{array}$ & $\begin{array}{l}\text { ons: } \\
109 \cdot 5(9 \cdot 8) \\
105 \cdot 3(1 \cdot 9) \\
100 \cdot 1(2 \cdot 8)^{*}\end{array}$ & $\begin{array}{l}61 \cdot 4(5 \cdot 5) \\
50 \cdot 0(3 \cdot 1)^{* *} \\
48 \cdot 6(3 \cdot 3)^{* *}\end{array}$ & $\begin{array}{l}47 \cdot 6(5.0) \\
40 \cdot 4(1 \cdot 9)^{*} \\
38 \cdot 4(2 \cdot 3)^{* *}\end{array}$ \\
\hline $\begin{array}{l}\text { Delay between shakin } \\
30 \mathrm{~s} \text { intervals } \\
10 \mathrm{~s} \text { intervals }\end{array}$ & $\begin{array}{l}\text { tuation: } \\
97 \cdot 8(4 \cdot 4)^{* *} \\
103 \cdot 5(5 \cdot 7)\end{array}$ & $\begin{array}{l}58 \cdot 6(2 \cdot 9) \\
56.4(3 \cdot 3)\end{array}$ & $\begin{array}{l}45.4(11.5) \\
41.9(1.9)\end{array}$ \\
\hline $\begin{array}{l}\text { Dose delivered by fir } \\
\text { Stem up } \\
\text { Stem down }\end{array}$ & $\begin{array}{l}\text { on: } \\
113 \cdot 4(7 \cdot 3) \\
81 \cdot 8(7 \cdot 2)^{* *}\end{array}$ & $\begin{array}{l}62 \cdot 5(5 \cdot 8) \\
45 \cdot 6(5 \cdot 2)^{* *}\end{array}$ & $\begin{array}{l}44 \cdot 6(3 \cdot 4) \\
32 \cdot 8(3 \cdot 5)^{* *}\end{array}$ \\
\hline
\end{tabular}

${ }^{*} \mathrm{p}<0.05 ;{ }^{* *} \mathrm{p}<0.01$. in suspension are generally formulated in such a way that the drug and propellant separate out rapidly. When formulated in this way the drug is easily resuspended upon shaking, while in formulations that settle out more slowly the drug tends to become caked onto the surface of the canister as it separates out and consequently is difficult to resuspend. ${ }^{6}$

Previous work has suggested that the first dose from an MDI should be wasted since storage for days ${ }^{7}$ or even hours ${ }^{8}$ may adversely affect the dose contained in the first actuation. A recent study showed that storage of salbutamol canisters with the valve stem down for as little as three hours resulted in a reduced dose in the first actuation. ${ }^{8}$ We also found a significant reduction in the first dose delivered when stored with the valve stem down, despite shaking, but if stored with the valve stem up there was no effect on total or respirable dose. This difference is presumably due to the metering chamber being in contact with propellant when stored with the valve stem down, allowing drug to leak out while the metering chamber is isolated from the propellant drug mixture with the stem up. Without further work, however, we could not recommend storage with the valve stem up as it is said that the sealing rubber gaskets can dry if not kept moist by propellants and surfactants, leading to possible valve dysfunction. ${ }^{9}$ Ironically, if the canister is stored valve stem up and not shaken, the first dose is likely to be the only one approximating to the nominal dose.

These results also imply that the recommendation of a one minute delay between actuations is unnecessary and, indeed, it is likely that this recommendation is rarely observed by patients. The concept that a one minute delay was necessary was based on the fact that cooling of the metering chamber occurs immediately after actuation of an MDI due to rapid boil or "flashing" of propellants as the chamber is open to atmospheric pressure. This may adversely affect the performance of the MDI in two ways. Contraction of the metering chamber due to cooling may reduce the volume of the next dose, ${ }^{5}$ and cooling of propellants in the chamber alters the characteristics of the aerosol generated on actuation by reducing the peak pressures generated within the chamber during flashing. ${ }^{111} \mathrm{~A}$ recent study has indeed shown that the performance of an MDI can be adversely affected when operated at a temperature close to freezing. ${ }^{11}$ However, cooling due to "flashing" of propellants will be transient and probably of short duration. Indeed, for this formulation a delay of five seconds appears adequate. It has been argued that a one minute interval between actuations can enhance the bronchodilator effect of the second dose by opening up the airways and allowing improved penetration of the second dose, but there is no evidence to support this assertion.

The one situation where rapid multiple doses are used most commonly is when using a large volume holding chamber, and our results suggest that introducing four doses rapidly into a chamber will reduce both the total and "res- patients.

These results emphasise the importance of shaking the device before use. When left overnight, the total and respirable dose was greatly reduced if the canister was not shaken even when the first two actuations were wasted. The reason for this is that MDIs containing drug

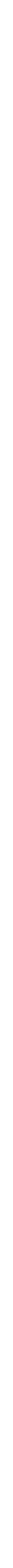


pirable" dose, independent of other possible sources of drug loss such as turbulence and coalescence within the chamber caused by successive actuations. ${ }^{1213}$ It is interesting to note that, when using four rapid actuations, the "respirable" dose falls by $18 \cdot 2 \%$ per actuation. This approaches the $25 \%$ reduction observed when four actuations of a different MDI formulation were introduced into a large volume chamber, ${ }^{14}$ suggesting that the greatest loss of "respirable" dose in this situation may be due to the use of rapid actuations. Two rapid actuations did not produce a significant effect on total drug delivery, again similar to the results of a previous in vitro study using a holding chamber. ${ }^{12}$ A recent study with salbutamol delivered via a large volume spacer found that the "respirable" dose fell by $21.9 \%$ when using two actuations, slightly more than the $15 \cdot 4 \%$ fall noted in our experiments, but when using three actuations it fell by $61.5 \%$. It is unclear why such a large fall was observed in that study. ${ }^{15}$

These results suggest that, to use a salbutamol MDI optimally, one should follow the instructions used for in vitro testing - that is, the canister should be shaken thoroughly before use and the first two actuations should be wasted. Any subsequent actuations can be carried out immediately after a 10 second breath holding period, providing the canister is shaken at least briefly during the interval,

Although these results, and those from previous studies, ${ }^{7}$ suggest that patients should waste the first two actuations before inhaling, this has significant implications in terms of drug wastage and cost. Our results suggest that, if the MDI is used in the same manner each time, wasting the first actuation would probably not improve reproducibility of the dose delivered and hence it is probable, for drugs such as steroids, that it is more important to be consistent with using the first or third actuation, rather than arguing that one should be used in preference.

These results were obtained using a specific formulation of salbutamol and are not necessarily applicable to all MDI formulations. Such information is valuable since it is much simpler to follow instructions for use if the reasons for recommending a particular procedure are easily understood. Studies such as these should be performed by manufacturers for each formulation and the results made available, particularly once formulations using chlorofluoro carbon replacements become available.

1 Newman SP, Clarke SW. Therapeutic aerosols. 1 - Physical and practical considerations. Thorax 1983;38:881-6.

2 Newman SP, Clarke SW. Aerosols in therapy. In: Moren F, Newhouse MT, Dolovich MB, eds. Aerosols in medicine. Amsterdam: Elsevier, 1985:304.

3 Allen \& Hanburys. Instruction leaflet for Becotide pMDI.

4 Fisons. Instruction leaflet for Intal pMDI.

5 Burge PS. Getting the best out of bronchodilator therapy. In: Clark TJH, Cochrane GM, eds. Bronchodilator therapy. Auckland, New Zealand: Adis Press, 1984:59.

6 Edman P. Pharmaceutical formulations - suspensions and solutions. F Aerosol Med 1994;7: S3-6.

7 Lourenco RV, Cotromanes E. Clinical aerosols. 1. Characterisation of aerosols and their diagnostic uses. Arch Intern Med 1982;142:2163-72.

8 Cyr TD, Graham SJ, Li KYR, Lovering EG. Low firstspray drug content in albuterol metered-dose inhalers. Pharmaceut Res 1991;8:658-60.

9 Moren F. Aerosol dosage forms and formulations. In: Moren F, Newhouse MT, Dolovich MB, eds. Aerosols in medicine. Amsterdam: Elsevier, 1985:273.

10 Wilson AF, Mukai DS, Ahbout JJ. Effect of canister temperature on performance of metered-dose inhalers. $\mathrm{Am}$ perature on performance of meter
Rev Respir Dis 1991;143:1034-7.

11 Hampson NB, Mueller MP. Cooling of metered-dose inhalers decreases pressure output from canisters. $N$ Engl $\mathcal{F}$ Med 1989;320:321.

12 Everard MI, Clark AR, Milner AD. Drug delivery from holding chambers with attached facemask. Arch Dis Child 1992;67:580-5.

13 Clark AR, Rachelefsky G, Mason PL, Goldenhersh MJ, Hollingworth A. The use of reservoir devices for the simultaneous delivery of two metered-dose aerosols. $\mathcal{f}$ Allergy Clin Immunol 1990;85:75-9.

14 Clark AR. In vitro assessment of spacer and reservoir devices. In: Dalby RN, Evans RM, eds. Respiratory drug delivery II. Lexington: University of Kentucky, 1992:470-82.

15 Barry PW, O'Callaghan C. Multiple actuations of salbutamol MDI into a spacer device reduce the amount of drug recovered in the respirable range. Eur Respir 71994 ; 7:1707-9. 